\title{
Práticas de gestão ambiental nos meios de hospedagem de Guaratuba (PR) na visão de seus gestores
}

\section{Management practices in lodging facilities from Guaratuba (PR, Brazil) through their managers' perspectives}

\author{
Elizabete Sayuri Kushano, Celso Maciel de Meira
}

\begin{abstract}
RESUMO
O presente trabalho teve como objetivo analisar o conhecimento dos gestores de meios de hospedagem do município de Guaratuba, litoral paranaense, quanto à Gestão Ambiental; assim como verificar, a partir da concepção dos mesmos, quais as práticas de sustentabilidade ambiental desenvolvidas nos empreendimentos em que atuam. Para delimitação do estudo, foram considerados os meios de hospedagem cadastrados junto ao Sistema de Cadastro de Pessoas Físicas e Jurídicas atuantes no setor do turismo (CADASTUR). Referente à metodologia, utilizou a pesquisa exploratória, do tipo qualitativa, por meio de entrevistas semiestruturadas, aplicadas a dez gestores. Os resultados apontaram que seus conhecimentos são relativos quanto ao tema e que são desenvolvidas algumas ações basilares, tais como a separação de resíduos sólidos e a utilização de lâmpadas LED. Em sua maioria, não receberam algum tipo de capacitação quanto ao referido assunto e parte considerável dos gestores não concebeu que as ações de GA podem ser diferenciais nas tomadas de decisões dos hóspedes, deixando de estabelecer relações com as vantagens competitivas que emergem a partir delas.

PALAVRAS-CHAVE: Gestão Ambiental; Meios de Hospedagem; Sustentabilidade; Guaratuba (PR).
\end{abstract}




\section{ABSTRACT}

This study aims to analyze the knowledge of the management department from lodging facilities in the city of Guaratuba, Parana, Brazil on Environmental Management and evaluate, from their point of view, which ambiental sustainable practices they have developed in the projects they work on. For delimitation of the study, we considered only the registered lodging facilities on CADASTUR (a registry system for both individuals and companies that work in the tourism industry). The methodology used was an exploratory research focusing on qualitative study, through semi-structured interviews, applied to 10 managers. The results showed that their knowledge is relative on the subject and that some basic actions are developed. In most cases, they have not received some kind of training on that subject and a considerable part of the managers did not conceive that Environmental Management actions can be advantageous for guests decisions, failing to establish relations with the competitive advantages that emerge from the decisions.

KEYWORDS: Environmental Management; Lodging Facilities; Sustainability; Guaratuba (PR, Brazil).

\section{Introdução}

O setor de hospedagem é um dos cinco pilares básicos do Turismo, assim como o de transportes, de gastronomia, de compras e de hospitalidade (OLIVEIRA, 2001). As empresas de meios de hospedagem, comumente são consideradas grandes geradoras de efluentes e consumidoras de energias, insumos e outros recursos naturais na composição de seus produtos e serviços. Somado ao exposto, decorrem impactos ambientais, quando não geridos de forma consciente, da produção dos resíduos, da utilização de equipamentos, dos produtos químicos utilizados, dos efluentes que são lançados nos rios entre outras problemáticas ambientais (CASTELLI, 1991; GONÇALVES, 2004).

No bojo dessas questões, estudos que envolvam os desdobramentos de uma série de produtos e serviços, componentes dos ciclos de hospedagem, se fazem necessários, visando à busca de alternativas que contribuam para mitigar seus impactos, notadamente, por motivos elementares, entre os quais: a situação ambiental adversa dos dias que correm; a sensibilização ambiental; a própria sustentabilidade do empreendimento e as possíveis vantagens competitivas que as ações de Gestão Ambiental (GA) podem proporcionar ao mesmo.

O presente trabalho teve como objetivo analisar o conhecimento dos gestores de meios de hospedagem do município de Guaratuba, litoral paranaense, quanto à Gestão Ambiental; assim como verificar, a partir da concepção dos mesmos, quais as práticas sustentáveis, em termos ambientais, desenvolvidas nos empreendimentos em que atuam; além de, observar se os gestores relacionam as práticas ambientais às vantagens competitivas da empresa. Para delimitação do estudo, foram considerados os meios de hospedagem cadastrados junto ao "Sistema de Cadastro de 
Pessoas Físicas e Jurídicas" - CADASTUR (BRASIL, 2016) atuantes no setor do turismo. Referente à metodologia, utilizou a pesquisa exploratória, do tipo qualitativa, por meio de entrevistas semiestruturadas, aplicadas a dez gestores.

Assim exposto, a presente pesquisa para a elaboração deste artigo, se justifica em decorrência do destino turístico de Guaratuba-PR, ao lado de Paranaguá, de acordo com o Plano de Desenvolvimento Integrado do Turismo Sustentável - PDTIS (PARANÁ, 2014, p.83), concentrar a oferta mais expressiva de unidade habitacionais da região turística 'Litoral do Paraná'.

A estrutura da exposição deste artigo, além da introdução que se apresenta, segue a partir dos seguintes tópicos: Gestão Ambiental nos Meios de Hospedagem; Resultados e Discussão e as Considerações finais.

\section{Gestão ambiental nos meios de hospedagem}

Pensando o funcionamento de um meio de hospedagem como sistêmico, no sentido que todas as partes são importantes e formam, em uníssono, o produto e serviço ofertado junto ao mercado turístico, há que se notar que, ainda são poucas as iniciativas que compõe o Sistema de Gestão Ambiental (SGH) de um empreendimento de hospedagem (CAON, 2008).

A principal finalidade de um SGH é alcançar, controlar e manter 0 nível de desempenho ambiental estabelecido pelas normas legais vigentes $\mathrm{e}$ relacionadas ao desenvolvimento sustentável (CAON, 2008).

Nesse sentido, Viterbo Jr. (1998, p.51), corrobora mencionando que:

O Sistema de Gestão Ambiental visa minimizar os impactos ambientais com ajuda da gerência, funcionários e hóspedes para que esses se conscientizem da importância de administrar os recursos naturais, reduzindo os impactos negativos, tanto para a pousada ( $\mathrm{sic}$ ) quanto para o seu entorno.

Sinteticamente, o mesmo autor (1998) salienta que, a gestão ambiental é uma forma da organização administrar as relações entre suas atividades e o meio ambiente que as abriga, observadas as expectativas das partes interessadas.

Muito embora, grande maioria dos meios de hospedagem existente no Brasil não estabeleça um SGH, propriamente dito, há que se considerar práticas de gestão ambiental que vem sendo desenvolvidas no setor.

Conforme observou Dias (2005, p.225),

A gestão ambiental é importante para os meios de hospedagem, pois além de contribuir para preservar o meio ambiente é também de grande auxílio ao desenvolvimento de uma empresa, colaborando com o aumento de renda e consequentemente, de enorme importância à sustentabilidade do empreendimento. 
Tal concepção vem ao encontro do pensamento de Barbieri (2007, p.65), que amplia a ideia das partes interessadas, quando salienta que:

\begin{abstract}
Pouco adianta as iniciativas de gestão nos níveis globais e regionais se não forem acompanhadas de iniciativas nacionais e locais. É no interior dos estados nacionais, de suas subdivisões, localidades, comunidades e organizações que ocorrem efetivamente as ações de gestão ambiental. As disposições dos acordos globais e regionais devem ser incorporadas nas legislações nacionais e locais para gerar efeitos sobre os agentes econômicos, produtos e consumidores.
\end{abstract}

A menção aos consumidores remete à questão das vantagens competitivas, visto que "[...] ao tempo em que crescem as expectativas do cidadão em relação à questão ambiental, crescem suas exigências enquanto consumidor" (BARBOSA FILHO, 2010, p.303). Assim, tais exigências não se dissociam das tomadas de decisões dos consumidores, cada vez mais atentos em relação aos seus consumos, quando estabelecem relações com as questões ambientais, tendo em vista a preocupação que as empresas devem ter com os ambientes onde estão localizadas.

Nesse contexto, para Gonçalves (2004, p.73):

O segmento de hospitalidade representa um caso interessante que expõe muitos conflitos que surgem com a implantação de políticas ambientais. Por exemplo, muitos hotéis e restaurantes estão situados em área de beleza natural, em cidades históricas e em regiões de delicado equilíbrio ambiental. A localização das operações de hospitalidade, como é o caso da maioria dos serviços, é definida em função das necessidades dos clientes e, portanto, não pode deixar de ser influenciada e influenciar o meio ambiente no qual está inserida.

Ainda, a questão da vantagem competividade no tocante aos consumidores, segundo a OMT (2001, p.259), parte da:

[...] constatação de que os consumidores preferem entornos bem conservados e atividades turísticas não predatórias e de que estão dispostos a pagar mais por isso, facilita a adoção de estratégias de sustentabilidade pela indústria turística e sua aliança mais sincera com os movimentos conservadores.

Para além das vantagens competitivas, o que está em evidência é a responsabilidade socioambiental inseparável das ações empresariais da atualidade, com base na sustentabilidade, assim como salienta Anjos et al (2010, p.145): 


\begin{abstract}
A sustentabilidade do desenvolvimento turístico exige a elaboração de metodologias integradas, abrangendo questões ecológicas, econômicas e socioculturais, e a formulação de estratégias de longo prazo, que inseriram o turismo dentro de uma perspectiva de desenvolvimento com objetivos de continuidade.
\end{abstract}

Nessa mesma direção, para Han e Yonn (2015) o processo de "esverdeamento" das empresas hoteleiras é visto como uma pré-condição essencial para se atrair e reter um número cada vez maior de clientes adeptos aos preceitos da sustentabilidade, que preferem e estão dispostos a comprar produtos com características verdes. Ainda, segundo tais autores, os hotéis ambientalmente responsáveis procuram realizar melhorias vitais em suas estruturas, diminuindo significativamente seus impactos negativos ao meio ambiente. Assim, são cabíveis algumas ações, entre elas os esforços contínuos para se identificar meios efetivos na diminuição da frequência da mudança e/ou da lavagem dos lençóis e toalhas (HAN; YONN, 2015).

Ressalta-se que para Gonçalves (2004, p.58), muito embora, tratando-se das necessidades ambientais da atualidade e dos efetivos resultados que a gestão ambiental pode proporcionar às empresas, do ponto de vista mercadológico, "[...] a grande maioria do empresariado não encara a atuação ambiental como fonte de vantagem competitiva para seus negócios, mas sim como custos". Tal situação pode encontrar relação com a carência de ou falta de absorção de formação profissional específica na área (BARBOSA FILHO, 2010).

Ademais, conforme salientado por Fogliatti (2008, p.6), "[...] qualquer que seja a empresa, indústria ou prestadora de serviços, no instante em que inicia sua instalação e/ou sua operação, inicia também sua própria deterioração e, em consequência, a do seu entorno". Nesse sentido, há que se pensar em mecanismos que aufiram a diminuição da deterioração, em prol da empresa e de seu entorno, o que, muitas vezes, envolve vidas e a qualidade das mesmas.

Santos e Santos (2015), em pesquisa sobre sustentabilidade e hotelaria, tendo realizado um estudo de caso no município de Nova Iguaçu, Rio de Janeiro, Brasil, apresentaram um estudo com os Índices de Gestão de Sustentabilidade (IGS), abarcando as dimensões: ambiental, sociocultural e política e a econômica.

Para a gestão da sustentabilidade ambiental, os seguintes requisitos foram considerados: preparação e atendimento a emergências ambientais na região; programa de proteção da fauna e da flora; arquitetura integrada à paisagem, compatível com o entorno físico e cultural; paisagismo que reflita o ambiente natural do entorno; medidas para reduzir, reutilizar ou reciclar resíduos sólidos; coleta seletiva; tratamento das águas residuais; redução de emissão de gases, ruídos e odores no ar; redução do consumo de energia; redução do consumo de água; medidas de captação de água da chuva; uso de águas residuais tratadas para rega, lavagem de veículos e outras 
aplicações; informação a clientes e funcionários sobre o comprometimento com a economia de água e energia; uso de produtos de limpeza biodegradáveis; controle de pragas de acordo com a legislação; compra de insumos minimizem impactos ambientais (SANTOS; SANTOS, 2015).

Iniciativas em gestão ambiental que partem da visão dos próprios empreendedores têm apresentado eficiência, como é o caso do Projeto Lixo Mínimo do Hotel Bühler, em Visconde de Mauá, RJ. Trata-se de um projeto ambiental desenvolvido pelos administradores do citado hotel, para minimizar os efeitos negativos da atividade turística sobre o meio natural (LAMAS, 2015). A autora descreve algumas ações do mesmo:

\begin{abstract}
A rotina de todos no hotel mudou em termos de que aos funcionários foi atribuída uma nova atividade, a de separar os resíduos sólidos em sua respectiva unidade de trabalho. $\mathrm{Na}$ cozinha, a separação é bem definida. Há pequenos recipientes para coleta de tampas e rolhas, e para dispositivos de acondicionamento para a coleta dos resíduos orgânicos e inorgânicos. Toda a sobra de líquidos é conduzida para os resíduos orgânicos. O óleo de cozinha possui recipiente próprio. Há, ainda, um escorredor exclusivo para o resíduo inorgânico, visto que o mesmo é lavado e secado antes de ser depositado em seu devido dispositivo de acondicionamento. Nas demais unidades do hotel (chalés, recepção, restaurante, área externa), os dispositivos de acondicionamento de resíduos também foram identificados, cada qual voltada para a coleta de um tipo específico de resíduo (LAMAS, 2015, p.152).
\end{abstract}

Lamas (2015) menciona também que na gerência, integrada à recepção, há um recipiente para o depósito de pilhas, baterias e lâmpadas usadas. Há instalação de sensores de presença nas unidades e uso lâmpadas com maior eficiência energética (maior durabilidade e menor consumo). Nos chalés, um material impresso colocado sobre a mesa da sala (e presente em outros materiais de divulgação dos serviços do hotel), descreve os tipos de resíduos e os recipientes apropriados ao seu descarte. $\mathrm{Na}$ sala há também um cartaz descrevendo o projeto Lixo Mínimo, disposto atrás da porta principal do chalé, e um dispositivo de acondicionamento identificado com a etiqueta "lixo inorgânico para reciclagem". Outra ação do projeto foi eliminar as bebidas em lata, dando preferência às garrafas de vidro, que retornam para o fabricante e, depois, voltam novamente cheias (LAMAS, 2015).

Ademais, os hóspedes também são convidados a participarem do projeto. Na entrada de acesso ao hotel há uma placa com os dizeres "Hotel Bühler, pioneiro na implantação do projeto Lixo Mínimo"; o que pode ocasionar resistência de alguns clientes, já que os mesmos são convocados a participar com a separação dos resíduos nas unidades do hotel (LAMAS, 2015). 
Outros desafios citados pela autora no que concerne ao projeto são: realizar contínuas pesquisas para manter ativo o projeto e não torná-lo obsoleto; definir um espaço para guardar o resíduo reciclável; o modo como ele será transportado e seu destino final; saber realizar a compostagem do resíduo orgânico para que seja eficiente e sanitariamente segura (LAMAS, 2015).

Há que se notar, também, a importância dos recursos humanos em projetos ambientais. Conforme Swarbrooke (2000), a relação entre recursos humanos e turismo sustentável tem duas dimensões principais: o turismo sustentável somente existe quando há uma força de trabalho sustentável; o modo como os trabalhadores são tratados tanto pelos gerentes, quanto pelos turistas, pois a sustentabilidade está relacionada com a igualdade social e justiça.

Em se tratando do tema da gestão ambiental nos meios de hospedagem na área territorial do litoral do Paraná, encontrou-se dois estudos referentes à llha do Mel (pertencente ao município de Paranaguá), ambos destacando a gestão de resíduos sólidos naquele destino (SPERB; TEIXEIRA, 2006; SPERB; TELLES, 2014).

No primeiro estudo, a partir de pesquisa empírica, conclui-se que não existe, na maioria dos empresários, a preocupação com a utilização sustentável dos recursos naturais e que as ações relacionadas ao uso desses recursos não são decorrentes de uma consciência ambiental coletiva (SPERB; TEIXEIRA, 2006). No segundo estudo, cujo instrumento de coleta de dados foi a entrevista junto aos empresários e representantes do setor público, os resultados indicaram que muitas das ações de tratamento e destinações dos resíduos sólidos aconteciam, geralmente, pelo livre arbítrio dos proprietários. Por parte do setor público, verificou-se ausência de estruturas físicas adequadas para a gestão dos resíduos sólidos, assim como de critérios claros para o tratamento e destinação destes resíduos e a falta de orientações efetivas aos empresários (SPERB; TELLES, 2014).

\section{Metodologia}

Em busca da delimitação para a pesquisa de campo, elegeram-se os meios de hospedagem cadastrados junto ao CADASTUR (BRASIL, 2016). Levantou-se que 11 meios de hospedagem se encontravam cadastrados no município de Guaratuba, dentre os quais se verificou as seguintes tipologias: pousadas e hotéis. Seguindo esse caminho, todos os meios de hospedagem, devidamente cadastrados, foram arrolados na pesquisa; porém, um gestor não aceitou realizar a entrevista.

$O$ instrumento de coleta de dados utilizado foi a entrevista semiestruturada, que foi aplicada aos gestores dos meios de hospedagem no período de 17 a 23 de junho de 2016.

Quanto à área de estudos, a palavra Guaratuba tem sua origem na língua tupi guarani, sendo seu prefixo ligado à expressão "Wa'ra" (garça, pássaro), seguido pelo sufixo (coletivo) "tüba", que significa muitos pássaros ou muitas garças. (PARANÁ, 2016). 
Em relação à história de constituição do município, tem-se que:

[...] originou-se à partir da ordenação da coroa portuguesa de criar um povoado na enseada de Guaratuba, selecionando 200 casais para povoarem o local, no ano de 1765. Cinco anos depois foi fundada a Vila de São Luiz da Marinha de Guaratuba. Em 29 de Abril de 1771, deu-se a solenidade de fundação da vila e como primeiro ato a celebração da Santa Missa. Nesta mesma data este povoado foi elevado à categoria de Vila, com a denominação de Vila São Luíz de Guaratuba da Marinha (PARANÁ, 2016, p. 24).

Guaratuba, em número de residentes, é o segundo maior município da região turística Litoral do Paraná, com uma população estimada em 35.182 habitantes, distribuída em uma área territorial de $1.326,791 \mathrm{~km}^{2}$.

Referente a seus limites geográficos, ao norte faz divisa com 0 município de Matinhos, ao Sul com Itapoá-SC, a leste com o Oceano Atlântico e a oeste com o município de São José dos Pinhais. Com relação aos acessos, tendo como base o município de Curitiba, o destino é servido por conservadas vias, com destaque às rodovias BR $277(116 \mathrm{~km})$, e por meio da BR 376 (131 km) (IBGE, 2016).

Dentre as atividades econômicas se destacam: o comércio, os serviços, a pesca, a pesca artesanal, a agropecuária e agricultura (em pequena escala), a silvicultura e a extração vegetal (IBGE, 2016). Todavia, são as atividades turísticas que dão números relevantes à realidade econômica do município, que tem forte fluxo de turistas, em sua maioria do âmbito regional, atraídos pelo turismo de sol e praia, seguidos pelo turismo de pesca, náutico, turismo de aventura (PARANÁ, 2010).

De acordo com o Plano de Desenvolvimento Integrado do Turismo Sustentável, Polo Litoral do Paraná - PDITS (PARANÁ, 2010) além dos atrativos naturais vinculados ao sol e praia, como as praias da Barra do Saí, das Caieiras, de Coroados e do Brejatuba, o município também possui atrativos de relevância para o ecoturismo como o Salto Parati, o Morro do Cabaraquara e a Lagoa do Parado, ambos localizados na Baía de Guaratuba.

A referida baía é a segunda maior do Estado (PREFEITURA MUNICIPAL DE GUARATUBA, 2016), caracterizada por ser um estuário são comuns as práticas da pesca, passeios de barco, e a realização de esportes náuticos, de fato, que permite "práticas esportivas como kite surf, wind surf $e$ mergulho" (PARANÁ, 2010, p.82).

Não diferente de outros municípios costeiros, o município se vale principalmente do turismo de sol de praia, tendo seus fluxos de visitantes na alta temporada, que corresponde aos meses de dezembro a março. $\mathrm{Na}$ área central da localidade, verifica-se uma grande concentração de segundas residências, notadamente, de famílias curitibanas, com a população local residindo em logradouros adjacentes (PIERRI, 2011). 
Nesse cenário, entre o presente e o passado, Guaratuba se (re) constrói, alicerçada por costumes lusitanos em meio a resquícios de costumes e tradições indígenas, contrastando com as manifestações do ser humano moderno.

\section{Resultados e Discussão}

Conforme mencionado no tópico Metodologia, foram entrevistados 10 gestores de meios de hospedagem do município de Guaratuba.

É válido destacar que nenhum dos meios de hospedagem enumerados possui classificação junto ao Sistema Brasileiro de Classificação dos Meios de Hospedagem - SBCLASS (BRASIL, 2015).

$\mathrm{Na}$ primeira questão, onde foi perguntado a formação do gestor, bem como o tempo na empresa, além da tipologia do meio de hospedagem no qual atua, as respostas foram compiladas a partir da Tabela 1:

Tabela 1: formação do gestor e tempo de serviço na empresa.

Table 1: manager training and time of service in the company.

\begin{tabular}{|l|l|}
\hline \multicolumn{2}{|l|}{ Qual sua formação? Tempo de empresa. Tipologia do Meio de Hospedagem } \\
\hline Entrevistado 1 & Superior incompleto -10 anos de empresa [Hotel] \\
\hline Entrevistado 2 & Superior incompleto -3 anos de empresa [Pousada] \\
\hline Entrevistado 3 & Superior incompleto -3 anos de empresa [Pousada] \\
\hline Entrevistado 4 & Arquitetura -04 anos de empresa [Hotel] \\
\hline Entrevistado 5 & Superior incompleto -5 anos de empresa [Hotel] \\
\hline Entrevistado 6 & Ensino fundamental -38 anos de empresa [Hotel] \\
\hline Entrevistado 7 & Graduação em História -18 anos de empresa [Hotel] \\
\hline Entrevistado 8 & $\begin{array}{l}\text { Graduação em Administração - } 7 \text { anos de empresa (proprietário) } \\
\text { [Pousada] }\end{array}$ \\
\hline Entrevistado 9 & Graduação em Administração - 16 anos de empresa [Hotel] \\
\hline Entrevistado 10 & $\begin{array}{l}\text { Curso de Técnico em Hospedagem - } 6 \text { anos de empresa } \\
\text { (proprietário) [Pousada] }\end{array}$ \\
\hline
\end{tabular}

Fonte: pesquisa de campo (2016). Source: field research (2016).

A partir das respostas à pergunta 1 , chegou-se à média de 11 anos de tempo de serviço dos gestores entrevistados. Os meios de hospedagem classificam-se em hotel e pousada. Um gestor, de meio de hospedagem cadastrado no CADASTUR não se disponibilizou para entrevista. Ademais, a partir das respostas observou-se que, em termos de formação, apenas o Entrevistado 9, possui formação específica na área de Hospedagem. Todos que mencionaram que tem superior incompleto não continuaram os estudos.

Tal constatação apoia-se com o que Barbosa Filho (2010), mencionou sobre a carência de profissionais qualificados ou mesmo a falta de absorção de tais profissionais, haja vista que são poucos os de formação profissional específica na área.

Para a pergunta 2: "possui algum conhecimento sobre gestão ambiental? Se sim, adquiriu na empresa, ou, provém de outras experiências profissionais? Todos responderam de forma afirmativa à primeira parte da pergunta. Referente aos conhecimentos sobre gestão ambiental, 8 dos entrevistados afirmaram que foram adquiridos de outras experiências 
profissionais. Assim como o Entrevistado 3, que mencionou: "Tenho algumas ideias de quando trabalhava num outro emprego, mas a experiência foi na área industrial". Porém, 2 deles mencionaram que foram adquiridos no próprio local de trabalho. Assim como o Entrevistado 9, que revelou: "meus conhecimentos são pertinentes à hotelaria, adquiridos na minha atuação profissional durante esses 16 anos".

As respostas a essa pergunta evidenciaram que os gestores adquiriram conhecimentos sobre gestão ambiental à partir da prática, muitas vezes de experiências vivenciadas em outras atuações profissionais. Estudos de caso como o apresentado por Lamas (2015), envolvem capitação continuada, além de sensibilização ambiental do próprio cliente.

Na pergunta 3: "a empresa pratica gestão ambiental? Se sim, quais são as práticas (ações)?”. Todos os gestores responderam que são realizadas algumas práticas:

O Entrevistado 1, respondeu: "preocupamos com a diminuição da lavagem do enxoval e pedimos aos hóspedes que reutilizem, principalmente, as tolhas. Separamos o lixo e procuramos dar um destino adequado. Fazemos, também, na medida do possível, economia de água".

Para o Entrevistado 2, "praticamos ações veiculadas pela mídia em geral, como, por exemplo: a substituição gradual de lâmpadas comuns por lâmpadas consideradas menos poluidoras. Também, tomamos cuidados com o descarte dessas lâmpadas e dos equipamentos em geral e separamos o lixo".

Já o Entrevistado 3 respondeu: "efetivamente, a separação dos resíduos é a nossa única prática".

A resposta do Entrevistado 4, foi a seguinte: "separação dos resíduos, conscientização aos hóspedes sobre uso racional de água, reutilização das toalhas de banho e na lavandeira, principalmente. Lá temos equipamentos que automaticamente reduzem o uso da água e de produtos utilizadas nas lavagens".

O Entrevistado 5 salientou:

Fazemos a separação do lixo e temos um local específico para armazenamento. Temos um poço para captação de água fluvial, e essa água é utilizada em alguns setores do hotel. Após a utilização da água captada, havendo algum risco de contaminação, não a lançamos diretamente ao meio ambiente, sem o devido tratamento. Outra prática, de acordo com a necessidade de reposição, trocamos as lâmpadas antigas por lâmpadas $L E D^{1}$, mais econômicas e menos poluidoras. Além disso, separamos e damos 0 direcionamento correto ao óleo de cozinha. Seria isso.

Também o Entrevistado 6, respondeu positivamente à questão e acrescentou: 
Separamos os resíduos. Trocamos, conforme a necessidade, as lâmpadas fluorescentes por lâmpadas de LED. Tem, também, um poço para captação de água fluvial, que utilizamos na lavanderia. Aliás, nós usamos placas indicativas e informativas no hotel, o que, acredito fazer diferença. Praticamente, é isso.

A resposta do Entrevistado 7 para a pergunta foi:

Separamos os resíduos e os descartamos corretamente. Também, direcionamos os equipamentos aos locais de coletas, principalmente, os televisores. A gente não joga nada fora do local apropriado. Espalhamos lixeiras pela praia, aqui próxima, e, também, sacolas de lixos, assim como orientamos e incentivamos nossos hóspedes a colaborar com as nossas ações. Além disso, todos os nossos apartamentos possuem placas solares.

Já o Entrevistado 8, respondeu: "Separamos os resíduos, mas a coleta, pela prefeitura, não é feita de forma adequada. Procuramos usar racionalmente a água e destinamos o óleo utilizado na cozinha para reaproveitamento".

O Entrevistado 9, afirmou: "veja, na lavanderia utilizamos produtos biodegradáveis, separamos o lixo, doamos o óleo utilizado na nossa cozinha para serem reaproveitados". O mesmo continuou descrevendo que "as fechaduras têm dispositivos que desativam automaticamente o sistema de energia do apartamento".

O Entrevistado 10 respondeu sucintamente: "separação do lixo. Substituição de lâmpadas comuns por lâmpadas de LED”.

As respostas a essa questão evidenciaram que a separação de lixo foi identificada como prática de gestão ambiental por todos os gestores pesquisados. Quatro deles também mencionaram a utilização de lâmpadas LED. Apenas um (1) mencionou o uso de placas informativas em relação às questões ambientais.

Nota-se que, em sua maioria, são ações basilares, vez que muitas outras iniciativas poderiam ser praticadas, conforme apresentado por Santos e Santos (2015), destacando: a arquitetura integrada à paisagem, compatível com o entorno físico e cultural; o paisagismo que reflita o ambiente natural do entorno; as medidas para reduzir, reutilizar ou reciclar resíduos sólidos; a redução de emissão de gases, ruídos e odores no ar; o uso de produtos de limpeza biodegradáveis, entre outros.

Para a questão 4: "a empresa oferece, ou já ofereceu algum treinamento ou capacitação referente à Gestão Ambiental?”, 8 dos 10 entrevistados disseram que não houve algum treinamento ou capacitação referente ao tema da gestão ambiental. Assim como o Entrevistado 2 que respondeu: "a empresa, até o momento, não ofereceu nenhum curso ou treinamento específico para gestão ambiental'. Os Entrevistados 8 e 10, 
foram sintéticos ao responderem que: "não". Já o Entrevistado 5 mencionou que: "fizemos um curso ao longo desses anos, foi de segurança contra incêndio". O Entrevistado 6 relatou que: "poucas vezes, mas já tivemos alguma preparação, inclusive, a última relacionada aos treinamentos para a Copa do Mundo". O Entrevistado 9, destacou: "Não temos nenhuma capacitação específica, mas temos algumas orientações nesse sentido, a partir das consultorias que contratamos".

Para a questão de número 5: "em relação às vantagens competitivas, em sua opinião as práticas de gestão ambiental tem ou teriam alguma relação com as tomadas de decisão de compra dos hóspedes? Em outras palavras, as ações de gestão ambiental influenciaria a escolha dos hóspedes ao vosso hotel?", as seguintes respostas foram dadas pelos entrevistados:

O Entrevistado 1 destacou que pode gerar vantagem competitiva, principalmente se as ações diminuírem o preço da diária. Porém, frisou: "mas, somente para as questões ambientais, em si, não é uma preocupação, mas na permanência do hóspede, somos elogiados em relação a algumas ações".

Já o Entrevistado 2 mencionou: "Não acredito que isso influenciaria, pois vejo que nossos hóspedes não tem esse perfil ecológico. Um exemplo: é uma minoria de pede sacolinha para levar à praia".

Pensamento semelhante adveio do Entrevistado 3, que destacou que de imediato não, e acrescentou: "pois creio que o preço está a frente de qualquer decisão. Mas, depois que conhecer o ambiente e verificar alguma prática, talvez as práticas gerem alguma vantagem competitiva".

Corroborando com tais pensamentos, o Entrevistado 4, opinou que: "não. Ou pouco provável, infelizmente. Normalmente, o que vejo são hóspedes procurando uma hospedagem mais em conta".

Para o Entrevistado 5, "acho que não, até poderia... Mas, em geral, os hóspedes não tem essa preocupação, não se verifica. Tem outra, nós não utilizamos as práticas que mencionei como publicidade".

O Entrevistado 8 respondeu apenas que "não". E os gestores dos meios de hospedagem 6, 7 e 9, tiveram uma perspectiva mais positiva quanto a essa questão. Para o Entrevistado 6 , há vantagens, mesmo que sejam poucas. O Entrevistado 7 respondeu: "Sim, gera vantagem competitiva e, assim, aumenta a possibilidade do hóspede ficar conosco. Se o hóspede ver algo que não seja adequado ambientalmente, ele vai embora". E, para o Entrevistado 9: "Acredito que sim, principalmente se as ações e práticas são veiculadas aos hóspedes de alguma forma. No nosso site já fazemos certa divulgação de nossas práticas, e isso tem dado retorno. Se não fizéssemos isso, acho que seríamos cobrados, pois os hóspedes perguntam".

Assim, para essa questão foram 4 gestores que responderam que as práticas de gestão ambiental influenciam nas tomadas de decisões dos hóspedes, enquanto 6 dos gestores disseram que não. 
Apontou-se no decorrer deste trabalho, citações como as de Barbosa Filho (2010); OMT (2001); Han e Yonn (2015), que relacionaram a gestão ambiental com as vantagens competitivas. Porém, conforme Gonçalves (2004) mencionou a grande maioria do empresariado não encara a atuação ambiental como fonte de vantagem competitiva para seus negócios.

Como dado complementar à pesquisa, verificou-se que apenas um site oficial dos meios de hospedagem que participaram deste estudo, faz menção às questões ambientais. Consta o texto que o hotel respeita e contribui para o bem-estar do planeta praticando ações sustentáveis e incentivando a participação e conscientização dos colaboradores e hóspedes, ajudando assim, na preservação dos recursos naturais. Destaca as seguintes ações: conscientes com nossas impressões, utilizamos frente e verso das folhas e papéis que seriam jogados fora para uso como rascunhos; fazemos o reaproveitamento do óleo de cozinha na produção de sabão; possuímos um sistema para economizar energia dos apartamentos, controlando e reduzindo o consumo; separamos os materiais recicláveis; informamos nossos clientes sobre a conscientização do uso das toalhas (HOTÉIS VILLA REAL, 2016).

\section{Considerações finais}

O tema da gestão ambiental nos meios de hospedagem é pertinente e alguns estudos, principalmente em nível nacional, foram mencionados ao longo deste trabalho.

O objetivo de analisar o conhecimento dos gestores de meios de hospedagem do município de Guaratuba sobre a gestão ambiental foi atingido. Assim como o de verificar, a partir da concepção dos mesmos, quais as práticas sustentáveis (na dimensão ambiental) desenvolvidas nos empreendimentos em que atuam. Além disso, a relação entre as práticas ambientais e as vantagens competitivas das empresas também foi assunto destacado.

Os resultados propalaram que os gestores dos meios de hospedagem têm conhecimentos relativos quanto ao tema e que são desenvolvidas, de modo geral, ações basilares, tais como a separação de resíduos sólidos e a utilização de lâmpadas LED. Em sua maioria, não receberam algum tipo de capacitação quanto ao referido assunto e parte considerável dos gestores não concebeu que as ações de GA podem ser diferenciais nas tomadas de decisões dos hóspedes, deixando de estabelecer relações com as vantagens competitivas que emergem a partir delas.

Algumas respostas chamaram a atenção no decorrer do estudo, tais como a do gestor que mencionou que os hóspedes que frequentam seu estabelecimento não têm o perfil ecológico. Caberia estudos que revelassem a visão dos turistas que visitam Guaratuba, nomeadamente um destino de sol e praia, para averiguar se os mesmos possuem sensibilização ambiental e se as práticas de gestão ambiental são consideradas por eles como diferenciais na escolha de um meio de hospedagem. 
Ademais, caberiam outros estudos que revelassem Índices de Gestão de Sustentabilidade (IGS), abarcando além da sustentabilidade ambiental, a sociocultural, a política e a econômica.

Em que pese o caráter qualitativo desta pesquisa, o fato das entrevistas terem sido realizadas a partir do contato pessoal, fez com que os pesquisados pudessem se expressar de modo claro aos pesquisadores, os quais buscaram transmitir isso a partir da transcrição das falas dos gestores, buscando contribuir para desvelar o cenário atual de parte do parque hoteleiro do município de Guaratuba, especialmente em se tratando do tema proposto.

\section{Referências}

ANJOS, F.A.; ANJOS; S.J.G.; RADOS, G.J.V. Planejamento e gestão sustentável do turismo: contexto social, métodos e enfoques. In: PHILLIPI Jr, A.; RUSCHMANN, D.V.M. Gestão ambiental e sustentabilidade no turismo. Barueri, SP: Manole, 2010.

BARBOSA FILHO, A. N. Segurança do trabalho \& gestão ambiental. 3.ed. São Paulo: Atlas, 2010.

BRASIL. MINISTÉRIO DO TURISMO. Sistema Brasileiro de Classificação de Meios de Hospedagem. Disponível em: <http://www.classificacao.turismo.gov.br/MTUR-classificacao/mtur-site/>.

Acesso em: 17 jun. 2015.

BRASIL. MINISTÉRIO DO TURISMO. Sistema de Cadastro de pessoas físicas e jurídicas que atuam no setor do turismo. Disponível em: $<$ http://www.cadastur.turismo.gov.br/cadastur/PesquisarEmpresas.action> Acesso em: 18 jun. 2016.

CASTELLI, G. Marketing hoteleiro. Caxias do Sul: Educs, 1991.

DIAS, R. Introdução ao turismo. São Paulo: Atlas, 2005

FERRETI, E.R. Turismo e meio ambiente: uma abordagem integrada. São Paulo: Roca, 2002.

FOGLIATTI, M.C., et al. Sistema de gestão ambiental para empresas. Rio de Janeiro - RJ: Interciência, 2008.

GONÇALVES, L.C. Gestão ambiental em meios de hospedagem. São Paulo: Aleph, 2004.

HAN, H.; YOON, H.J. Hotel customers' environmentally responsible behavioral intention: Impact of key constructs on decision in green consumerism. International Journal of Hospitality Management, v.45, n.1, p. 22-33, 2015.

IBGE Cidades. Guaratuba. Disponível em: <www.cidades.ibge.gov.br> Acesso em: 9 mai.2016.

LAMAS, A. S. Gestão de Resíduos Sólidos em Meios de Hospedagem: Um Estudo de Caso do Projeto Lixo Mínimo do Hotel Bühler em Visconde de Mauá, RJ. Revista Rosa dos Ventos - Turismo e Hospitalidade, n. 7, v.1, p. 147-161, jan-mar, 2015. 
ORGANIZAÇÃO MUNDIAL DO TURISMO (OMT). Introdução ao turismo. São Paulo. Roca, 2001.

PARANÁ. Secretaria de Turismo. Plano de Desenvolvimento Integrado do Turismo Sustentável Polo Turístico do Litoral Paranaense (PDTIS LP). FAUUEPG, Ponta Grossa, 2010.

PARANÁ. Secretaria de Turismo. Guia Litoral do Paraná. Disponível em: <http://www.turismo.pr.gov.br/arquivos/File/GuiadoLitoral2015.pdf>. Acesso: 05.jul.2016.

PIERRI, N. Litoral do Paraná: uma leitura dos limites de sua sustentabilidade socioambiental. Palestra proferida em 10 jun. 2011. UFPR.

SANTOS, R.A; SANTOS, M.R. Sustentabilidade e Hotelaria: Um Estudo de Caso no Município de Nova Iguaçu, Rio de Janeiro, Brasil. Turismo \& Sociedade. Curitiba, v. 8, n. 3, p. 446-466, set.-dez. de 2015.

SPERB, M.P; TEIXEIRA, R.M. Turismo Sustentável e Gestão Ambiental no Setor Hoteleiro: o Caso da llha do Mel. IV SeminTUR - Seminário de Pesquisa em Turismo do MERCOSUL. Anais...Caxias do Sul, 2006.

VITERBO Jr, E. Sistema integrado de gestão ambiental. São Paulo: Aquariana, 1998.

\section{Nota:}

1 O diodo emissor de luz, também conhecido pela sigla em inglês LED (Light Emitting Diode), é usado para a emissão de luz em locais e instrumentos onde se torna mais conveniente a sua utilização no lugar de uma lâmpada. Especialmente utilizado em produtos de microeletrônica como sinalizador de avisos, também pode ser encontrado em tamanho maior, como em alguns modelos de semáforos. Também é muito utilizado postes de iluminação pública, permitindo uma redução significativa no consumo de eletricidade (FONTE: https://pt.wikipedia.org/wiki/Diodo emissor de luz). Acesso em: 25 de ago. 2016.

Elizabete Sayuri Kushano: Universidade Federal do Paraná, Curitiba, PR, Brasil.

E-mail: xsayurix@gmail.com

Link para o currículo Lattes: http://lattes.cnpq.br/0012178721094020

Celso Maciel de Meira: Universidade do Estado de Mato Grosso, Nova Xavantina, MT, Brasil.

E-mail: celsotour@gmail.com

Link para o currículo Lattes: http://lattes.cnpq.br/9170108842312860

Data de submissão: 30 de agosto de 2016

Data de recebimento de correções: 31 de julho de 2017

Data do aceite: 31 de julho de 2017

Avaliado anonimamente 